\title{
Anemia and Iron Deficiency Anemia Prevalence with Serum Zinc assessment among Emigrated Yazidis People in Khanki camp in Duhok city, Kurdistan Region, Iraq.
}

\author{
Hani M. Ahmad \\ (Medical Laboratory Technology Dept., Shekhan Technical College of Health, Duhok Polytechnic University, \\ Duhok, Iraq)
}

\begin{abstract}
:
Back ground and Objective: Iron deficiency anemia is a widespread health problem and associated with many complications, while its association with zinc deficiency is still uncertain. The aim of this study was to evaluate the prevalence of Anemia and Iron Deficiency Anemia then to assess the serum zinc status and its relation to the iron deficiency anemia among emigrated Yazidis people, in Khanki camp in Duhok city, Iraqi Kurdistan region. Materials and Methods: This study consist of two parts, the first is cross sectional, to determine iron deficiency anemia and anemia prevalence. The second part of this study is a case control, to investigate the serum level of zinc and its significance among individuals with iron deficiency anemia. Assessment of serum ferritin and blood hemoglobin were used to diagnose anemia and iron deficiency anemia. The study performed in 2015-2016, among 1400 emigrant Yazidis people, divided into five groups. Then serum zinc values were estimated among 200 individuals with iron deficiency anemia and 100 healthy controls. All these data were analyzed statistically. Results: Statistical analysis indicated that (38.7\%) of whole age groups presented with anemia and the pregnant women showed the highest prevalence (59.9\%). On the other hand, $48.1 \%$ of whole age groups presented with low serum ferritin, and the highest prevalence (66.1\%) found among pregnant women group. Iron deficiency anemia observed in (25.5\%) of total participants with the highest prevalence in pregnant women group (32.6\%). The mean concentration of serum zinc for the first group (200 cases) was $56 \pm 16.44 \mu \mathrm{g} / \mathrm{dl}$, which is significantly $(P$ value $<0.001)$ low in comparison to the control group in which the mean concentration of serum zinc was $82 \pm 12.27 \mu \mathrm{g} / \mathrm{dl}$.

Conclusion: Iron deficiency anemia has a high prevalence among residents of this camp, especially among pregnant women. In addition, there was a strong significance between iron deficiency anemia and low serum zinc. These results suggest the need for iron and zinc supplements for treatment of the current deficiencies and prevention of more cases.
\end{abstract}

Keywords: children, Duhok, ferritin, hemoglobin, Iraq, men, preschool, zinc.

\section{Introduction}

Anemia is a worldwide health challenge, common in developed and developing communities with serious health, social and economic consequences. It can affect all age groups, but with highest prevalent among pregnant women [1]. According to WHO reports, most of the world's nations may have iron deficiency and about 2 billion people worldwide have iron deficiency [2]. Anemia is still a serious health challenge to developing countries with high prevalence despite national health programs [3]. Anemia is an actual telltale of destitute health and nutritional status, and its high prevalence in the developing countries has a genuine bad effects on community health, including poor pregnancy outcome, increased risk of maternal and child mortality, impairment of cognitive and physical development of children, impaired school performance, and decreased productivity. $[4,5,6,7]$.

Variety of causes can lead to anemia, but globally, the most significant contributor is iron deficiency, and this is the cause for synonymous use of iron deficiency anemia and anemia terms. Generally, iron deficiency is the major cause for about $50 \%$ of anemic cases. The most common causes of iron deficiency anemia include a low intake of iron, poor intestinal absorption, and increased iron requirements during pregnancy and body growth [4].

Iron deficiency, considered to be the most common cause of anemia, but other nutrients deficiencies such as vitamin B12, folic acid, and recently, contribution of zinc can cause different forms of anemia [8]. Also anemia can occur due to other causes like, excessive menstrual blood loss, malignancies, parasitic infections such as schistosomiasis, and chronic infections such as tuberculosis and malaria. Low serum ferritin leads to diagnosis of the iron deficiency (which means depletion of iron stores) because it is an accurate measurement of body iron stores even in non-anemic patient when blood hemoglobin and serum iron concentration are normal. In human being, the total iron store is in close association with serum ferritin level. Thus, serum ferritin 
concentration is the best laboratory indicator to assess the actual iron stores status. Occasionally, iron deficiency anemia will occur when there is insufficient iron supply to keep normal level of hemoglobin in individuals with normal blood hemoglobin and iron deficiency (low serum ferritin) [9].

Blood hemoglobin determination is usually used to assess the prevalence of anemia among different populations. In 2001, WHO determined the cut-off values of blood hemoglobin according to age, gender and physiological status. Then the 2004 joint WHO/CDC technical consultation confirmed that, ferritin concentration can be used as an indicator of iron depletion [10,11]. However, acute infection or inflammation can cause an increase of serum ferritin because ferritin is an acute phase reactant, so the C-reactive protein should be measured to confirm the presence of acute infection or inflammation as a cause for high serum ferritin. [12, 13].

Nutritional zinc deficiency affects around 2 billion subjects worldwide. Meat products are the richest source of zinc, while cereal proteins which are high in phytate can decrease the absorption of zinc. Zinc is an important contributing factor of many cellular metabolic processes, Over 300 enzymes require zinc for their activation and about 2000 transcription factors need zinc for expression of genes but its rule in pathogenesis of anemia is still uncertain [14]. A daily intake of zinc is required to preserve the normal state and this is due to a fact that human body have no specialized zinc storage system [15]. Zinc deficiency is usually more common in children, because higher daily requirement of zinc, also in pregnant women and women on weight-reducing diets $[16,17]$.

Zinc distribution throughout the body as a component of nucleic acids and of different types of protein make it difficult to measure zinc status adequately using laboratory tests $[18,19]$. However, serum zinc level is the most reliable commonly used laboratory test for assessing zinc deficiency, although clinical presentations of zinc deficiency can occur even in the absence of abnormal laboratory test result [20,21].

\subsection{Study Design and Setting}

\section{Materials \& methods}

This study, was conducted during 2015-2016 in Khanki camp which is located in Duhok city, Iraqi Kurdistan region. Performed among Yazidis people, which are a religious minority population group, emigrated mainly from Sinjar city (because of ISIS attacks) and characterized by poverty and specified nutritional habits. This camp contains a total of 18700 individuals since two years. Randomly, 1400 individuals were selected, then divided into five groups: preschool age children ( $<6$ years), school-age children (6-16 years), pregnant women (no age range defined), non-pregnant women (>16 years), and men (>16 years). Exclusion criteria involved individuals with fever, inflammation, acute or chronic infection, malignancy, history of recent or frequent blood transfusions, and diagnosed or suspected cases of hemolytic anemia.

\subsection{Laboratory assessment}

From all participants, venous blood samples were obtained for hematological and biochemical tests. Two types of test tubes were used to collect blood samples, one for hemoglobin estimation (collected in EDTA tubes). The second blood sample collected in plain test tube (without EDTA), allowed to clot at room temperature, centrifuged to get the serum then tested for serum ferritin and serum zinc. Blood hemoglobin measured by Sysmex hematological analyzer, while serum ferritin measured by Cobas e 411 immunology analyzer, these instruments were calibrated and became under tight quality control monitoring during the whole measuring process. Serum zinc levels were measured using a Colorimetric Method Zinc Assay Kit (QuantiChrom TM Zinc Assay Kit (DIZN-250 / BioAssay System). Although, still there is no WHO cut-off values for serum zinc, serum zinc level (66 -120 $\mu \mathrm{g} / \mathrm{dl}$.) depended as a normal reference range and zinc deficiency was defined as a serum zinc level $<66 \mu \mathrm{g} / \mathrm{dl}$. The WHO cut-off levels were depended to identify anemia and iron depletion (serum ferritin) in different groups. [22]

\subsection{Data analysis}

Statistical Package for the Social Sciences (SPSS), version 13.0 used to analyze the data. While proportional differences of data done by using Chi's square test. Blood hemoglobin concentrations and sample characteristics were examined with descriptive statistics.

\section{Results \& discussion}

In this study, blood hemoglobin and serum ferritin were measured among 1400 participants enrolled and classified into 5 groups. Table (1) shows the mean concentration of blood hemoglobin, serum ferritin and the prevalence of anemia and iron deficiency. Then serum zinc value estimated in 200 individuals diagnosed with iron deficiency anemia and 100 healthy controls, table (3) shows the results.

\subsection{Hemoglobin results}


Blood hemoglobin concentration and anemia prevalence were determined among the studied five groups (1400 individuals) (Table 1). Mean hemoglobin concentration were varied among different groups, the least was among pregnant women $(9.1 \pm 1.8)$, while the highest was among men group (13.8 $\pm 4.2 \mathrm{~g} / \mathrm{dl})$. This variation was expected, due to the effects of age, sex and physiological state. Mothers show the highest prevalence of anemia $(59.9 \%)$, then preschool children $(47.6 \%)$, school age children $(37.5 \%)$, non-pregnant women $(26.1 \%)$, while least anemia prevalence was among men group $(18.7 \%)$. The overall anemia prevalence was $(38.7 \%)$ and this result pointed to anemia as a prominent health trouble among studied community (Fig. 1). The prevalence of anemia among this population (Yazidis people) not reported before, this mean that comparison is not applicable for these results to other studies.

\subsection{Ferritin results}

The total iron store is best assessed by serum ferritin concentration, so the depleted iron store is reflected by low ferritin level and hence it's a predisposition condition to iron deficiency anemia. Among 1400 participants, the mean concentration of serum ferritin was highest among men group $(32.4 \pm 8.6 \mu \mathrm{g} / \mathrm{l})$, while the least concentration was among pregnant women group $(8.4 \pm 2.7 \mu \mathrm{g} / \mathrm{l})$. This made the prevalence of iron depletion among pregnant women the highest $(66.1 \%)$, followed by preschool children (59.6\%), school age children $(53.2 \%)$, non-pregnant women $(30.2 \%)$, while least prevalence was among men group $(24.6 \%)$. The overall iron depletion prevalence was $(48.1 \%)$ and this result makes this population highly susceptible to develop iron deficiency anemia in the future (Fig. 2). Highest prevalences of anemia and iron depletion were observed in pregnant women group, $(59.9 \%, 66.1 \%)$ respectively, and these results indicate the need of pregnant women for prompt nutritional and iron supplementation health program. While the least prevalences of anemia and iron depletion were observed in men group (18.7\%, 24.6\%) respectively (Fig. 3).

Table (1): - Mean concentration of hemoglobin and serum ferritin.

- Prevalence of anemia and of iron depletion.

\begin{tabular}{|c|c|c|c|c|c|c|c|}
\hline \multirow{2}{*}{$\begin{array}{c}\text { Age } \\
\text { group }\end{array}$} & \multirow[t]{2}{*}{ Number } & \multicolumn{3}{|c|}{ Blood Hemoglobin } & \multicolumn{3}{|c|}{ Serum Ferritin } \\
\hline & & "Mean Conc. $(\mathrm{g} / \mathrm{dl}) \pm \mathrm{SD}$ & $\begin{array}{c}\text { Number of } \\
\text { Anemic }\end{array}$ & $(\%)$ & $\begin{array}{c}\text { Mean } \\
\text { Conc. }(\mu \mathrm{g} / \mathrm{l}) \\
\pm \mathrm{SD}\end{array}$ & $\begin{array}{c}\text { Number of iron } \\
\text { depleted }\end{array}$ & $(\%)$ \\
\hline $\begin{array}{l}\text { Preschool } \\
\text { age } \\
\text { children }\end{array}$ & 317 & $9.8 \pm 3.3$ & 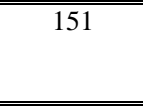 & "47.6* & $8.4 \pm 2.7$ & 189 & "59.6* \\
\hline $\begin{array}{c}\begin{array}{l}\text { School } \\
\text { age } \\
\text { children }\end{array} \\
\end{array}$ & 248 & $11.4 \pm 2.6$ & 93 & $37.5^{* *}$ & $9.1 \pm 4.7$ & 132 & $53.2^{* * *}$ \\
\hline $\begin{array}{c}\text { Pregnant } \\
\text { women }\end{array}$ & 322 & $9.1 \pm 1.8$ & 193 & "59.9* & $10.2 \pm 3.2$ & 213 & $66.1 * *$ \\
\hline $\begin{array}{c}\begin{array}{c}\text { Non- } \\
\text { pregnant } \\
\text { women }\end{array} \\
\end{array}$ & 241 & $11.2 \pm 3.1$ & 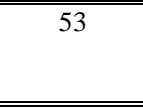 & $26.1 * * *$ & $26.6 \pm 6.8$ & 73 & $30.2^{* * *}$ \\
\hline Men & 272 & $13.8 \pm 4.2$ & 51 & $18.7 * * * *$ & $32.4 \pm 8.6$ & 67 & $24.6^{* * *}$ \\
\hline Total & 1400 & & 542 & 38.7 & & "674 & 48.1 \\
\hline
\end{tabular}

Blood Hemoglobin concentrations (Anemia): *<11 g/dl; **<11.5 g/dl; ***<12 g/dl; ****<13 g/dl Serum Ferritin concentrations (Iron depleted): $*<12 \mu \mathrm{g} / \mathrm{l} ; * *<15 \mu \mathrm{g} / \mathrm{l}$

\section{INDIVIDUALES}

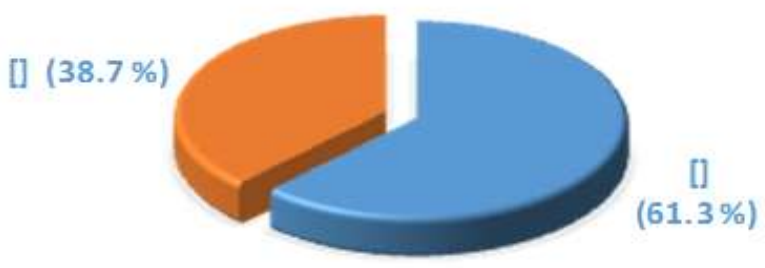

Figure (1) Prevalence of anemia among total studied population. 


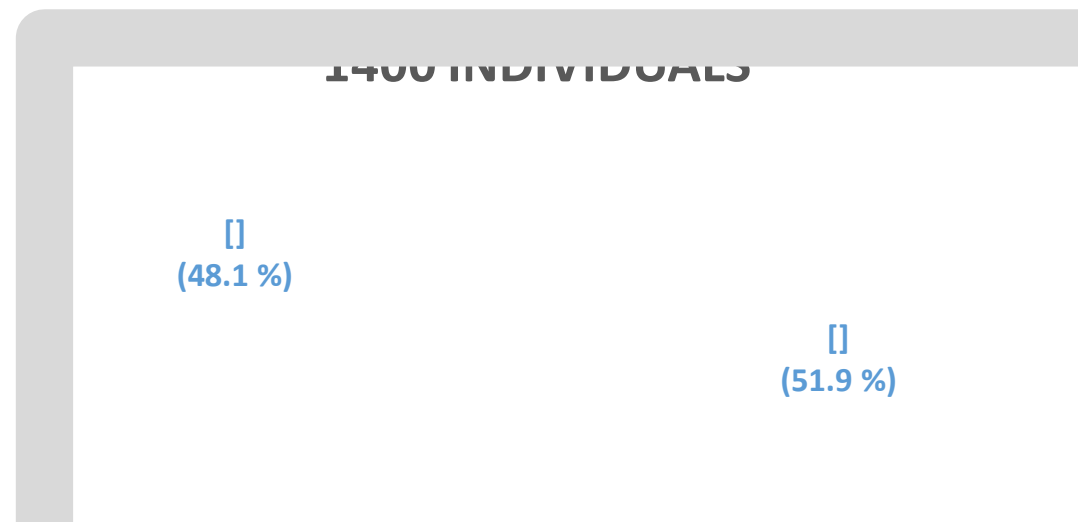

Figure (2) Prevalence of Iron depletion among total studied population.

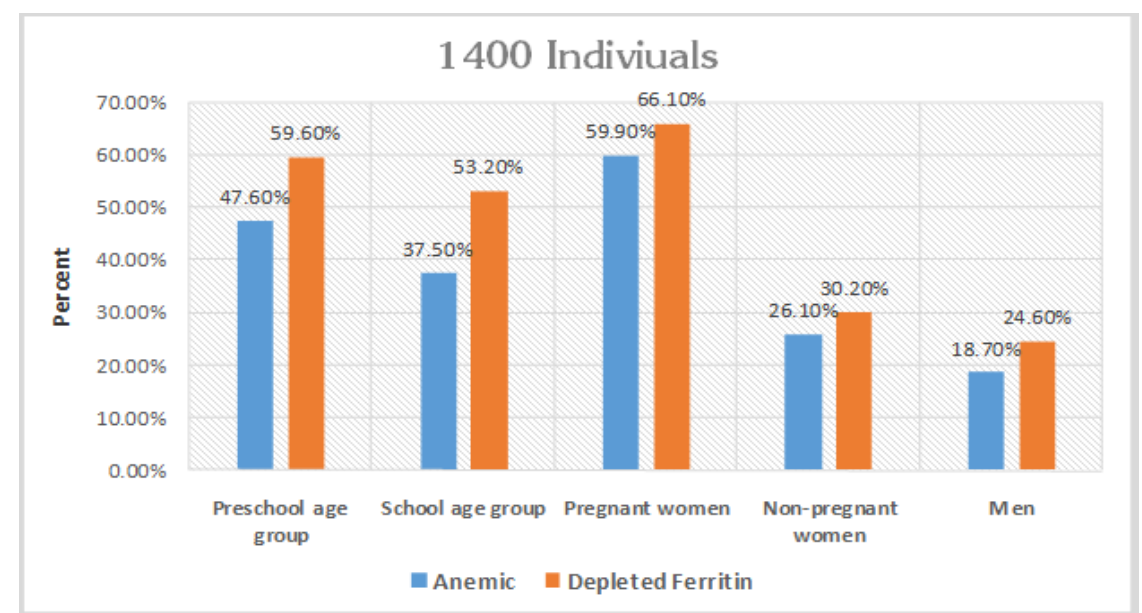

Figure (3) Prevalence of Anemia and Iron depletion among population groups.

\subsection{Blood hemoglobin/serum ferritin interlacement}

Among total studied population (1400 participants), iron deficiency showed a higher prevalence in comparison to anemia (48.1\% versus $38.7 \%$ ) according to the results of blood hemoglobin and serum ferritin (Table1). Depending on this relation, the studied population further analyzed and divided into four groups (Table 2), (Fig. 4). First group presented with iron deficiency anemia (low hemoglobin with low ferritin), diagnosed in 357 participants (25.5\%). Second group was anemic (low hemoglobin) with normal serum ferritin, diagnosed in 185 participants $(13.2 \%$ ). Third group was non-anemic with iron depletion (normal hemoglobin with low ferritin), diagnosed in 317 (22.6\%) and can be considered as a hidden iron deficiency anemia that can be shifted soon to clinically and laboratorial frank iron deficiency anemia. Finally, the fourth group included normal individuals (normal hemoglobin with normal ferritin), diagnosed in 541 (38.6\%).

Statistical analysis of data of each population group individually (Figure 5), revealed that the highest prevalence of iron deficiency anemia was in pregnant women group (32.6\%), and the least prevalence (14.9\%) was in men group. The highest prevalence of normal participants (normal blood hemoglobin with normal serum ferritin) was in the men group (56.8\%) while the least prevalence was in pregnant women group $(20 \%)$. The highest prevalence (29.6\%) of hidden iron deficiency which includes participants with normal hemoglobin and depleted iron store was in school age children (these individuals more susceptible to develop iron deficiency anemia in future due to increased iron needs because of growing of muscle mass and increasing of blood volume, while the least prevalence $(16.1 \%)$ found in men group. 
Table (2): Blood hemoglobin/serum ferritin interlacement among total studied population.

\begin{tabular}{|c|c|c|c|c|c|c|}
\hline & \multicolumn{2}{|c|}{ Hemoglobin } & & & \\
\hline & & Anemic & Non-anemic & & & \\
\hline \multirow[t]{4}{*}{ Ferritin } & \multirow[t]{2}{*}{ depleted } & 357 & 317 & Number & 674 & \\
\hline & & 25.5 & 22.6 & $\%$ & 48.1 & \\
\hline & \multirow{3}{*}{$\begin{array}{c}\text { not } \\
\text { depleted }\end{array}$} & 185 & 541 & Number & 726 & \\
\hline & & 13.2 & 38.6 & $\%$ & 51.9 & \\
\hline & & 2542 & 858 & Number & 1400 & Total \\
\hline
\end{tabular}

\section{INDIVIDUALS}

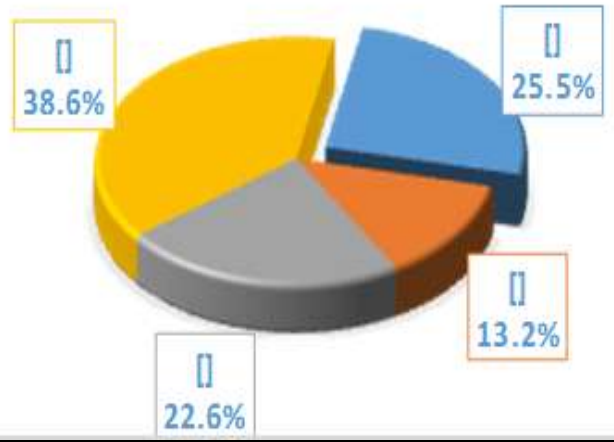

Figure (4) Hemoglobin / ferritin interlacement among total studied population.

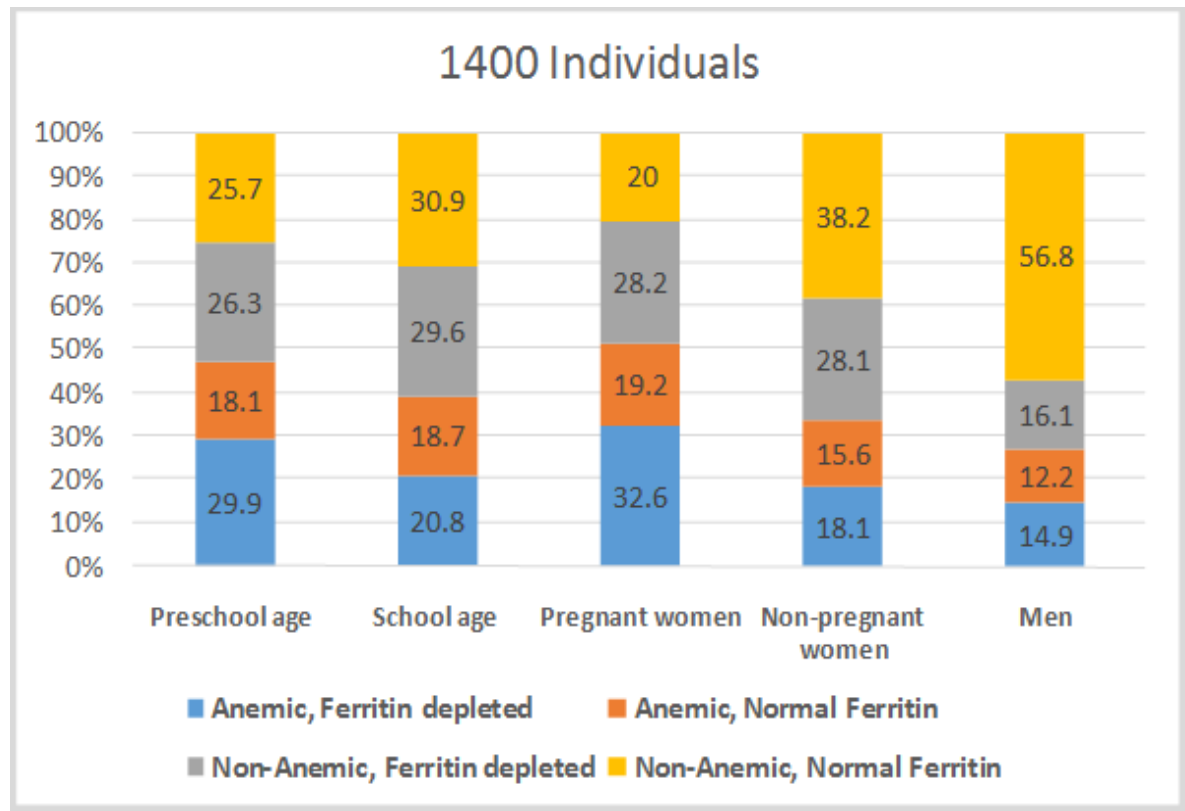

Figure (4) Hemoglobin / Ferritin interlacement among different groups.

\subsection{Serum zinc results}

Among 357 participants (diagnosed with iron deficiency anemia), 200 individuals were randomly selected and among 541 participants (considered healthy individuals with normal hemoglobin with normal serum ferritin), 100 individuals were randomly selected. Then serum zinc concentration estimated in these 2 groups, 200 cases and 100 controls (Table 3). The mean concentration of serum zinc was $56 \mu \mathrm{g} / \mathrm{dl}$ among 
individuals with iron deficiency anemia which is below the lower limit of normal reference range, while the result among the control group was $82 \mu \mathrm{g} / \mathrm{dl}$ which is within normal reference range. Statistically, a significant difference noticed between the two groups, $(\mathrm{P}<0.001)$.

Table (3): serum zinc mean concentration

\begin{tabular}{|c|c|c|c|}
\hline Group & Number & $\begin{array}{c}\text { Zinc mean concentration } \pm \\
\text { SD }\end{array}$ & \multirow{2}{*}{ P-value } \\
\hline Iron Deficiency Anemia & 200 & $56 \pm 16.44 \mu \mathrm{g} / \mathrm{dl}$ & $<0.001$ \\
\hline Control & 100 & $82 \pm 12.27 \mu \mathrm{g} / \mathrm{dl}$ & \\
\hline
\end{tabular}

Normal reference range: $66-120 \mu \mathrm{g} / \mathrm{dl}$

\section{Conclusion \& recommendations}

In general the residence of this camp showed high prevalence of Anemia (38.7\%) and iron deficiency anemia (25.5\%). Pregnant women showed the highest iron deficiency anemia prevalence, followed by preschool children, while the highest prevalence of hidden iron deficiency anemia (normal hemoglobin with low serum ferritin), which are facing high risk to develop iron deficiency anemia was among school age children. Serum zinc was obviously low in individuals with iron deficiency anemia and shows a significant difference in comparison to control group. These results suggest the necessity of followings:

1. Assessment of blood hemoglobin and serum ferritin among all pregnant women, preschool children and school age children to diagnose iron deficiency anemia and hidden anemia and then to treat the cases.

2. Educational health programs and improving the nutritional status of the camp residents.

3. Combined zinc and iron supplementation is necessary for treatment of zinc deficiency in individuals with iron deficiency anemia.

4. This study has its own limitations and bias, so more expanded assessment and survey may be needed with more investigations like serum iron, transferrin, serum transferrin receptor and $\mathrm{C}$ - reactive protein.

\section{Acknowledgements}

Appreciation and thanks to all Laboratory technicians, participant residents and people who supported the study with help, wise suggestion and statist.

\section{References}

[1]. World Health Organization. The World Health Report 2002: Reducing risks, promoting healthy life. Geneva, World Health Organization, 2002.

[2]. Poskitt, Elizabeth ME. Early history of iron deficiency anemia. British Journal of Hematology 2003 ;122(4): $554-562$.

[3]. Nutrition and anemia. In: National Family Health Survey (NFHS - 3) 2005-06; volume 1, chapter 10. P

[4]. WHO (2001). Iron Deficiency Anemia Assessment, Prevention and Control. A guide for programme managers. Geneva: Switzerland: World Health Organization WHO/UNICEF/UNU. P. 114.

[5]. Zimmermann, M.B. and Hurrell, R.F. 2007 Nutritional iron deficiency. Lancet. Aug 11; 370 (9586):511-20.

[6]. Nadadur, S.S.; Srirama, K. and Mudipalli, A. (2008). Iron transport and homeostasis mechanisms: Their role in health and disease. Indian J Med Res.; 128:533-44.

[7]. Wood, R.J. and Ronnenberg, A. Iron. In: Shils ME, Shike M, Ross AC, Caballero B, Cousins RJ, editors. Modern Nutrition in Health and Disease. 10th ed. Baltimore: Lippincott Williams \& Wilkins; 2005. pp. 248-70.

[8]. WHO \& FAO (2004). Vitamin and mineral requirements in human nutrition, 2nd ed. World Health Organization, Food and Agricultural Organization of the United Nations.

[9]. Hallberg, L.; Bengtsson, C.; Lapidus, L.; Lindstedt, G.; Lundberg, P.A. and Hultén, L. (1993). Screening for iron deficiency: an analysis based on bone-marrow examinations and serum ferritin determinations in a population sample of women. Br. J. Haematol. Dec; 85(4):787-798.

[10]. WHO/CDC (2007). Assessing the iron status of populations, 2nd ed. Report of a joint World Health Organization/Centers for Disease Control and Prevention technical consultation on the assessment of iron status at the population level. Geneva: World Health Organization.

[11]. UNICEF/UNU/WHO (2001). Iron deficiency anemia: assessment, prevention and control, a guide for programme managers. Geneva: World Health Organization.

[12]. Baynes, R.; Bezwoda, W.; Bothwell, T.; Khan, Q. and Mansoor, N. (1986). The non-immune inflammatory response: serial changes in plasma iron, iron binding capacity, lactoferrin, ferritin and C-reactive protein. Scand. J. Clin. Lab Invest.; 46:695-704.

[13]. Gabay, C. and Kushner, I. (1999). Acute phase proteins and other systemic responses to inflammation. N Engl J Med.; 340:448- 54

[14]. Prasad AS. (2012). "Discovery of human zinc deficiency: 50 years later.". J Trace Elem. Med. Biol. 26: 66-69.

[15]. Rink L, Gabriel P. Zinc and the immune system. Proc Nutr Soc 2000; 59:541-52.

[16]. Yanagisawa, H.: Clinical aspects of zinc deficiency. The Journal of the Japan Medical Association 2002; 127(2): 261-268.

[17]. Tomita, H.: Taste Disorder and Diet. Kodansha Ltd., Tokyo, 2002; pp.3-140. (in Japanese)

[18]. Hunt JR. Bioavailability of iron, zinc, and other trace minerals from vegetarian diets. Am J Clin Nutr $2003 ; 78$ (3 Suppl):633S-9S

[19]. Van Wouwe JP. Clinical and laboratory assessment of zinc deficiency in Dutch children. A review. Biol Trace Elem Res 1995; 49:211-25.

[20]. Maret W, Sandstead HH. Zinc requirements and the risks and benefits of zinc supplementation. J Trace Elem Med Biol 2006; 20:318.

[21]. Yanagisawa, H., Kurihara, N. and Wada, O.: Zinc-Extensive blood and urine biochemistry and immunological tests (2).

[22]. WHO (2001). Iron Deficiency Anemia Assessment, Prevention and Control. A guide for programme managers. Geneva: Switzerland: World Health Organization WHO/UNICEF/UNU. P. 114. 